\title{
PRACTICE MANAGEMENT
}

\section{Table top sterilization}

Getinge's tabletop sterilizer range now includes the new HS22 K Series. According to Trycare Ltd, they feature square chambers, ensuring their volumes can be used to maximum capacity, and faster programmes.

The result is sterilizers that hold up to ten instrument trays and sterilize them within 25 minutes. The $\mathrm{K} 5$ holds five cassettes measuring up to $290 \times 190 \times 40 \mathrm{~mm}$, while the K7 holds five cassettes measuring up to $290 \times 190 \times 40 \mathrm{~mm}$ and five mini cassettes measuring up to $186 \times 145 \times$ $39 \mathrm{~mm}$. Other features include easy operation and stainless steel water tank Reader response number 55

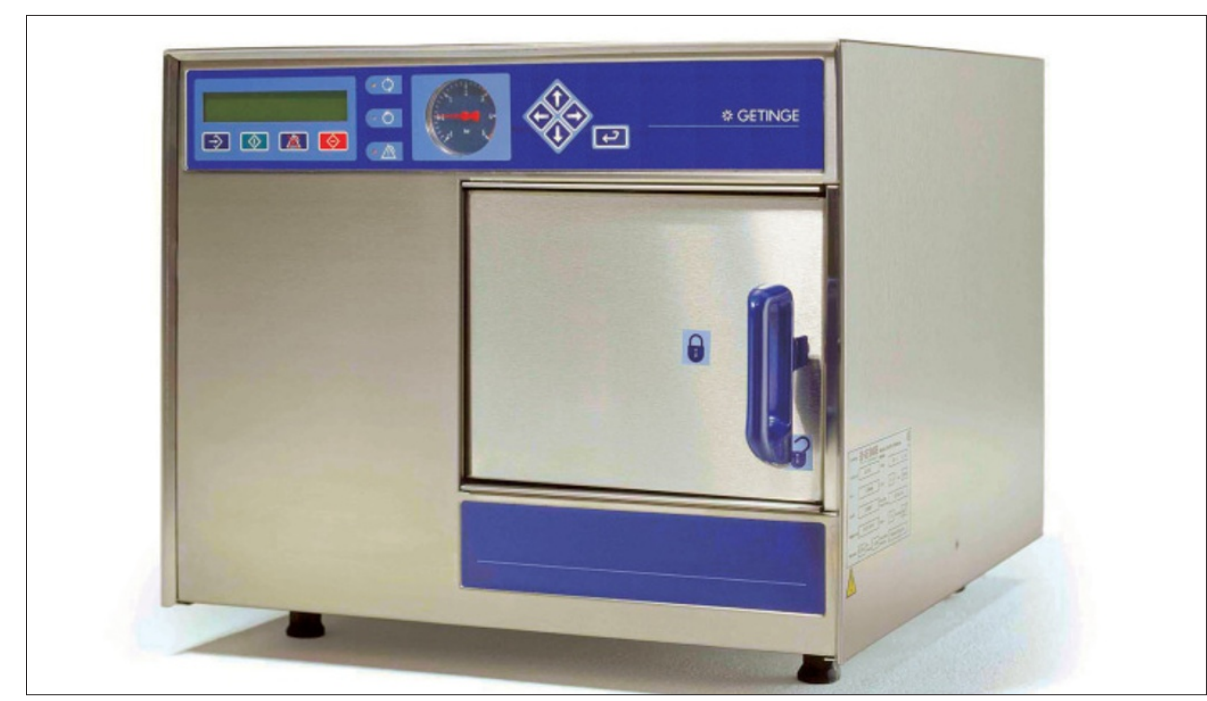




\section{Opportunity knocks}

Practices can make the most of opportunities to market to their patients while they wait with the PIC, the Practice Information Centre from MediVision. The computer software contains marketing material including informing the patient how the practice runs, promoting sundries, educating patients about oral health issues and promoting the services that the practice provides, or practice specialties.

There is a choice of over 200 marketing messages and powerful 3D animations and practices can select the sequence, frequency and duration of the message.

The Clinical Information Centre (CIC), is another product from MediVision. It is furnished with powerful 3D graphics of dental treatments to reinforce recommendations. The illustrations are clear and simple to understand but have been carefully designed not to distress patients.

According to the company, CIC reduces the time spent explaining treatments and overcomes language barriers. It features 55 $3 \mathrm{D}$ animation sequences, 55 patient leaflets and over 1500 dental clipart images. Reader response number 56
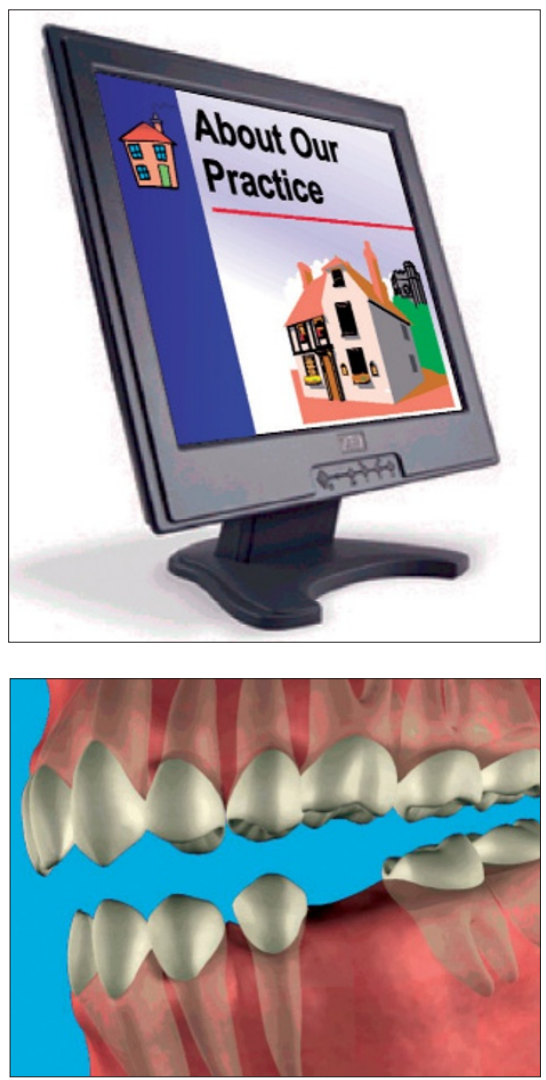

\section{Recording results}

It is now possible to accurately record a full soft tissue examination for oral cancer and lesions with Practice Works R4 dental practice management system, according to its manufacturer.

R4 not only caters for basic visual and palpation examination but will also record, in depth, the findings of toluidine blue-based mouthwash.

In addition to graphic screens $\mathrm{R} 4$ can also store notes for a specific lesion and associate intraoral or digital camera images with notes.

Reader response number 57

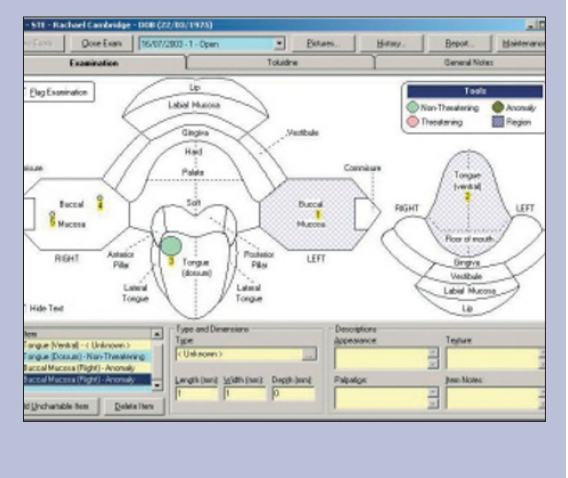




\section{Flexible solutions}

Software of Excellence have added Software Rental to their list of current options. This allows the flexibility to get up and running with a practice solution that meets a practice's needs, whether with Advance $\mathrm{XP}$ as a robust, efficient practice management system or with EXACT.

The rental scheme gives great flexibility, allowing capital to be used for other investments. There is no annual contract, and no lease commitments and just one month rental in advance.

The system can also reduce risk, as if a practice subsequently decides a computer system is not suitable, or the local Primary

\section{CPD credit}

Smile-on and Denplan have developed a new package to help dentists meet the terms of service requirement to complete 15 hours of peer review or clinical audit by April 2004.

The package, 'Clinical Audit Made Simple', can give you up to 16 credit hours of CPD for just £99. Five audit areas are covered; antimicrobial prescribing, crown assessments, periodontal record keeping, radiographs and waiting times. For each audit area, the CD-rom / online course and booklet package provides a brief demonstration of the process, while also supplying practical tools that you can use in conducting the audit.

In addition to clinical audit, Smile-on has over 17 hours of verifiable online CPD. Courses cover clinical and business subjects. You can choose an individual course or pick Smile-on's Five-Hour package at $£ 100$, the Ten-Hour package which saves $£ 29$; or the 15-Hour package which fulfils all your annual verifiable CPD for £370 + VAT.

Reader response number 59

\section{Stylish furniture}

The Dental Directory works with a leading specialist cabinetry provider to bring you a range of reception desks, storage cabinets, display areas and seating options.

All are crafted using quality materials and come in a range of styles to integrate perfectly within the practice. A complimentary planning service is also provided so that the design can be tailored to an individual's need and budget. To finish the effect, the company can also source a range of artificial plant displays that are almost indistinguishable from the real thing, to ensure the right ambience is created to complement the stylish new furniture.

Reader response number 61
Care trust decides to provide one, the company will turn off the use of the software and stop collecting the monthly payments. Reader response number 58
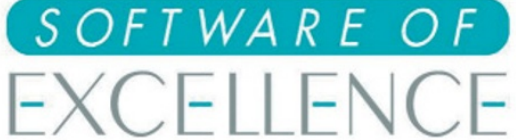

\section{Paperless practice}

EXACT8 computer software allows practice staff to see planned treatments in appointment windows. In addition, they can monitor which appointments have been made, which patients have arrived and in the case of non-arrivals, a reason for cancellation.

Also, if a patient is late staff can record exactly how late they were, and conversely they can detail if they were seen early or on time.

Bigger surgeries will also find the 'return to waiting room' option useful. An additional feature allows family appointments to be made 'en bloc' as opposed to a series of consecutive individual bookings.

With all the diary management and notes features there is a colour coding option to allow different appointment notes to be differentiated at a glance. 'Pop Up Notes' can also be entered to tailor the appointment to the individual, for example, as a reminder to ensure payment is taken at their next visit. Reader response number 60

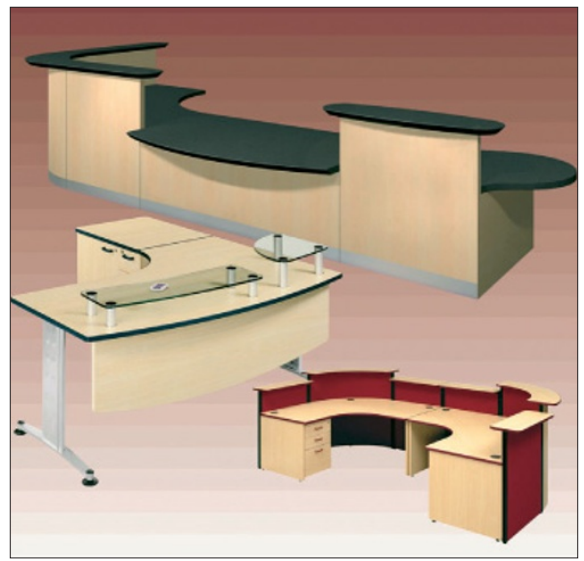

